\title{
Money is time: On the possibility of critique after neoliberalism
}

\author{
Leigh Claire La Berge \\ City University New York, USA
}

At the end of his Capital and Time: For a New Critique of Neoliberal Reason (2018), Martijn Konings offers a brief reflection on the methodology of critical thought itself. "It is not possible to provide an objective set of criteria for what makes knowledge critical”, he writes. Then, turning to a problem that he has considered and rejected in his book as a possible approach to the study of finance, that of performativity, he continues: "A good critique is a performative achievement; we recognize it when we encounter it" (205). It's an odd way to end a book that, I think, in many ways does provide a model for social theory. Likewise, it seems to me that the critical operation does contain a certain positive set of features, including a selfconsciousness of critical terminology and an ability to explain it in a vocabulary both endogenous to and foreign to its own origins; an awareness of the scale of abstraction at which the categories of analysis operate; and the resources to acknowledge when and why the scale of the abstraction changes, as it likely will need to in order to respond reflexively to whatever it encounters. Finally, the critical operation must distinguish its own sense of narrative - a kind of consistency of meaning over time - from argument, an assertion of why that consistency of meaning should persist in the face of difference. Another way of saying this: critique must be cognizant of its own deployment of the categories of time (argument) and space (abstraction). How, then, should this process confront an object that makes fundamentally temporal demands, namely money, and its constituents in a society organized around their investment and hoped-for realization, namely a financialized society? As its title indicates, Capital and Time sets its sights methodologically and historically on these precise concerns.

Konings' book now joins texts such as Philip Mirowski's Never Let a Serious Crisis Go to Waste (2013), Douglas Holmes' Economy of Words (2013), Perry Mehrling's The New Lombard Street (2010) and Karen Ho's Liquidated (2009) in seeking to explore not only what transpired during the 2007-8 global credit crisis, but what logics preceded that event and which of these would be able to remain operative after it. Before the 2007-8 crisis and subsequent recession, there was already a burgeoning, interdisciplinary field of work on financialization. Sometimes called 'cultures of finance', sometimes 'critical finance studies', those interested in this field saw their ranks grow quickly after the dramatic events of that year. After all, who doesn't love a

\section{Corresponding author:}

Leigh Claire La Berge, Department of English, 199 Chambers Street, New York, NY 10008, USA.

Email: llaberge@bmcc.cuny.edu 
period-ending, global crisis? Everyone got on board. Liberals to say: they saw it coming. Conservatives to claim: people brought it on themselves. Financiers themselves to say: no one could understand what was happening - it was too complex. Other financiers to say: everyone understood perfectly well what was happening, and that the bailouts would come were endtimes encountered. In exploring this new configuration and periodization of value embodied in governmental and private financial institutions, scholars began to produce a body of knowledge that would necessarily investigate the ontology of money, theories of the state, and the historical conditions of possibility for the emergence and denouement of speculative financial activity. We now have, in Konings' book, a consideration of some of the scholarship to have come out of this moment. Capital and Time attempts to take stock not only of recent financial history, but of finance-inflected knowledge production itself. If modernity, figured as liberalism, was a discounting of the future in hopes of a more secure present - as Konings, following Melinda Cooper (2011) suggests - then late modernity, or neoliberalism, is a valorization of the limits of calculability. How late modern subjects, states, and quasi-state institutions navigate that limit, what kind of knowledge they produce to do so, and, likewise, what kind of knowledge they produce to obfuscate that fact, becomes the central pivot of Konings' book, which aims to critique this epistemology by selecting 'neoliberal reason' as its object. That specification is important. Konings seeks, then, a reorientation of some of the basic premises of the critique of contemporary, finance-oriented political economy.

If the object of knowledge is finance, if the object of knowledge is neoliberalism, if the object of knowledge is reason itself, then the project of the critical operation will have to be modified to appropriately suit the object being criticized. One has to bend toward one's object in order to assume the object's own local discourses and idioms. And yet, if one bends too much, the critical project is stymied, becoming descriptive at best, and tautological at worst. What Konings finds in the critique of speculation is similar to what John Kenneth Galbraith (1990: 19) said about financial operations: "The world of finance hails the invention of the wheel over and over again, often in a slightly more unstable version". Now, according to Konings, this repetition has become a part of critiques of finance as well. The eternal return of the critique of finance, one that Konings traces back to Aristotle, is that of speculation, or a moralistic concern that some essential property of money is being trespassed against. Konings suggests that, most recently, this concern has undergirded much of the criticism of the 2007-8 (but in many ways, ongoing) crisis. And with this misplaced concern comes a misplaced solution: if we could only get back to fundamental values, sound values, productive values, we'd be able to have a less crisis-prone economy. That structural misrecognition has produced a wellspring of others, and Konings' cataloging of these tendencies is a call for scholars to remain precise in the organization of their criticism. He finds that the cause has been mistaken for the effect (in the case of speculative insecurity); the effect mistaken for the cause (in the case of performativity); the critique mistaken for the aim (in the case of neoliberalism). Thus he writes that: "Polanyian thought revolves around a systematic, selfreferential moment that it is unable to theorize" (62). Of the performative turn, he suggests that "performativity theory has mirrored rather than accounted for the paradoxical character of performatives" (66). Critics of neoliberalism, it might be said, have mistaken a narrative - a story - for a logic: a set of unfolding procedures. The story they have told (themselves) is that modes of economic expansion and contraction wax and wane; they expand to a certain limit and then, when that limit is reached, they are forced into contraction. Thus, this particular crisis has been read as the inevitable conclusion of an unsustainable financial expansion. But Konings insists not only that the critique of speculation is a problem, but that the conditions of that critique are already a symptom that has been mistaken for a cause. We can't get 'back to' 
the soundness and comfort of anti-speculative social organization because, as Gertrude Stein famously said in a different context, 'there's no there there'.

But at least we can understand why that is. For Konings, 'reason' results from the elaboration of a position on an object of security that allows one access to the past, the ability to maneuver in the present, and the resources to stake a claim on the future: that object is money. To know what is reasonable, rational, and or radical, one has to formulate a critique of money. Many critics of money, however, have sought to allow it exceptional status. They have sought to elevate money to a stable position of neutrality above the fray of the social world that generates money and then, from that place of conceptual stability, they have offered an understanding of what money is and what it does. Konings, following Minsky, insists otherwise: money always already stakes a claim on itself; it is always already imbricated in a social world in which it might be over-valued and devalued as a reflection of that social world itself. As Miranda Joseph (2014: $\mathrm{x}$ ) has recently noted, "debt is always the result of knowledge production". For Konings, so is money. Thus his project bears certain similarities to Alfred Sohn-Rethel's Intellectual and Manual Labor: A Critique of Epistemology (1978). For SohnRethel, epistemology is a reflection of the coordinates of labor and exchange at a particular moment in history, one that finds its symptomatic, capitalist apex in Kant's Critique of Pure Reason. What conception of labor as an activity in one's mind and in one's world, Sohn-Rethel asks, could have motivated Kant's conceptions of time and space as a priori categories? If Kant was the first modernist, as Clement Greenberg (1960) maintained, because he used reason to criticize reason, then money makes a particular, even pragmatic, claim on the stakes of the modern because the practice of using it and the philosophy toward using it become somewhat indistinguishable. Konings argues that modern money forces a radical reduction in the conceptual space available between a position of immanence and transcendence. This is undoubtedly true and likewise why it is problematic to claim, as Konings surprisingly does, that somehow life is more economic now, in late modernity than it was before, in early modernity. He might have appealed to the Foucault of The Order of Things (2005) and of the epistemic break into modernity, rather than of the biopolitics and the Lectures at the Collège de France $(2007 ; 2008)$ to undergird that claim.

If money is the object that grounds and orients reason, both liberal and neoliberal, then reason has to contend with that fact that "money signifies the impossibility of non-speculative signification", and in binding that contradiction together, becomes "the closest thing we have to security" (87). Thus, the problem for both epistemology and critique is that the closest thing we have to security is hardly secure. The term Konings introduces to undergird his critique of the shifting fortunes of money, one intimately related not to knowledge or reason but to those two constructions in their specific relation to money, is leverage. In place of speculation as the grounds of criticism, Konings outlines the concept of leverage as it organizes social time and space. Leverage is fundamentally speculative without insisting on anything fundamental about speculation. It is centrally oriented toward money without essentializing what money is: instead, money remains an ongoing, necessary contingency. Leverage may be seen as the temporal extension of modern, monetary self-referentiality. It may likewise be seen as a dynamic, contingent, and temporally-based substitution for the stale and conservative "human capital'. To be a creature of modernity, one is forced to leverage what one has. One can't recuse oneself from leveraging. One cannot get outside of a leveraged world. Indeed, the only way out is in: to leverage oneself to the point that, if the extension pays off, one might eventually opt out, a rare occurrence indeed. Banks leverage and people, through banking, become entwined with leveraging. Leverage is intended to work on multiple levels of abstraction as a social term, a historical term, a subjective term, and an instrumental term. 
Konings explains that "the concept of leverage is proposed here as a way to understand and control and influence as operating immanently. Power never comes to rest in outside institutions or symbols but always works relationally and performatively ... relational forms are immanent yet constitutive" (27). But again, for moderns, whatever forms of knowledge and power at work must be understood so as to position oneself in the present as it cedes into the future, and the binding technology for doing so is money itself.

Leveraging, then, offers a way for modern subjects to respond when faced with the most modern of paradigms, namely the knowledge that money is knowledge, a construct that is inescapably self-referential. The realization of this factuality produces anxiety in the subject; it also reveals to her an opportunity: perhaps I have realized this before others. Perhaps I might make a little money off this fact. Unfortunately, everyone else will necessarily have the same idea! And, in a self-referential system, to know is to be known, and so on, ad infinitum. 'Leverage' seeks to navigate this historical and discursive economic field. A financial term which Konings will amplify into the social field, it is a kind of metaphor; a transfer of certain qualities from one object to another, both a noun and verb. The choice of term itself metonymizes the very project: his critical term has to be both monetary and non-monetary simultaneously; much as Adorno (1970: 33) said of modern art, "it is constantly practicing the impossible trick of trying to identify the non-identical". Does it work? What does it offer critics of contemporary political economy and what does it neglect?

I found Konings' consideration of the state of the field both enlightening and convincing, and I appreciate the hopes he has for the concept of leveraging. His argument is specific, energetic and organized, and, as in his trenchant The Emotional Logic of Capitalism (2015), he demonstrates a wonderful ability to deconstruct the tautologies and false dichotomies on which so much of what passes for criticism are based. Where I found the project in need of more such energy and bibliographic resourcing was, paradoxically, at the site that Konings hopes to contribute to the discipline, namely the world of language, discourse, signification, and referentiality as each turns on itself to constitute a space of knowledge. Konings largely discounts 'ideology' in his study. Fair enough, I guess, although his critique of it seems to position it as a kind of stale Marxist notion of untruth and false consciousness. But there is a material world and there is an affective world and what mediates the two is largely left unexplored in this book. Indeed, affect is a term used over and over again but one largely left undefined. This weakness is particularly apparent in one of his later chapters on the affects that student debt engenders in the subject. Why do students go into debt? To try to leverage their abilities, to attempt to get ahead and achieve some sort of professional fulfillment and economic security. And yet the path to economic security requires them to pass through an expanded, overly contractualized, indeed, punitive world of economic insecurity. What does affect mean in this capacity? Is there a site of resistance? What, besides the need for leverage, motivates students to remain students? This is one of the few non-banking based examples of how the need to leverage takes a real, material form. But it simply doesn't do justice to the rich theoretical edifice which Konings has constructed. Indeed, it is too concrete and disappoints as an example. Yet another example is found in early modern and late Renaissance double-entry bookkeeping, in which the need to create a space of temporal nonidentity as a possible site of profit is given, in this case, textual form. But again, to me, the example falls flat.

What is the time/space space, then, between the lived social forms that the need to leverage takes and the production of that space through a world in which the pursuit of value runs up against the structural emptiness of its own construction? Let's take Konings' opening epigraph from Perry Mehrling, whose essence is palpable throughout the whole book: "The 
most real thing is money, but money is nothing more than a form of debt ... The whole system is therefore fundamentally circular and self-referential. There is nothing underneath, as it were, holding it up" (1). How are we to make money, and meaning, under these conditions? Konings relies on Niklas Luhmann's notion of "self-referentiality" in order to "understand how systems endogenously generate their conditions of possibility" (57). From this, Konings suggests that: "To view life through the lens of self-referentiality ... is a way of framing the paradoxical phenomenon of determination coming into being in a world that has no external mover" (57). He qualifies that "systems are self-referential not in the sense of being selfsufficient or autonomous but in the sense of having no outside foundation" (76). One of Konings' criticisms of Luhmann is that he "never meaningfully registers the fact that one of its central organizing concepts - self-referentially - receives an extremely pronounced manifestation in the self-expansion and self-valorization of finance capital" (90). And this, in a sense, is his project, to combine the organizing emptiness of money's groundless signification with the temporality of finance itself: its need always to look forward and to create, as the word's own etymology suggests, an end point against which some value can be realized. Finance, of course, comes from the French, fin (the end) and the associated verb, finir (to end). Leverage is a temporal form; one cannot do it instantaneously, rather, it takes time. In that sense, Benjamin Franklin's old line, that 'time is money,' might be reversed, money is time.

Konings speaks of his own project as interdisciplinary, but, in fact, I think it would have benefited from a few more disciplines, literary studies in particular. This may seem surprising to some readers of Finance and Society. And yet, for almost twenty years now, literary studies has investigated how time, narrative and the presumed indexicality of language all take new form in a financial era. In 1997, Fredric Jameson published an essay with the rather blunt title, "Culture and finance capital", which sought to explore the narrative, or temporal, dimensions of cultural forms that are produced under and respond to the age of finance capital. The stakes are different, of course, because Jameson is concerned with how the convergence of finance's reorganization of temporality affects cultural forms, many of which are time-based (novels, films, music, and so on). Literary scholars like Jameson engage and read much of the social scientific material that Konings so deftly assembles. But our hierarchies of disciplinary knowledge mean that cross-disciplinary traffic moves largely down a one-way street; humanities reads social science but social science does not read humanities. Why is that the case? What might a parallel story of modernity that focused on the creation of disciplinary knowledge in relation to a credit-based economy have offered Konings' account of neoliberal reason? That is, in many ways, a Foucaultian question, and here I thought of Mary Poovey's $A$ History of the Modern Fact (1998), which begins with the same double-entry bookkeeping that Konings turns to, and, in particular, her more recent Genres of the Credit Economy (2008) which, again, is concerned with how codified knowledge emerges from the play of representation, duration and signification that a credit-based economy both depends on and produces. This is not to make the argument that Konings should have written a different book - far from it. But it is to say that a certain transparency - so forcefully disbarred in his study from money itself - is allowed for disciplinary knowledge production as well as for language, and in a financial, or simply, modern, society, those too are self-referential forms. 


\section{References}

Adorno, T. (1970) Aesthetic Theory. Minneapolis, MN: University of Minnesota Press.

Cooper, M. (2011) Complexity theory after the financial crisis: The death of neoliberalism or the triumph of Hayek? Journal of Cultural Economy, 4(4): 371-85.

Foucault, M. (2005) The Order of Things: An Archaeology of the Human Sciences. London: Routledge.

Foucault, M. (2007) Security, Territory, Population: Lectures at the Collège de France, 1977-78.

Basingstoke: Palgrave.

Foucault, M. (2008) The Birth of Biopolitics: Lectures at the Collège de France, 1978-79. Basingstoke:

Palgrave.

Galbraith, J.K. (1990) A Short History of Financial Euphoria. New York, NY: Viking Press.

Greenberg, C. (1960) Modernist Painting: Forum Lectures. Washington, DC: Voice of America.

Ho, K. (2009) Liquidated: An Ethnography of Wall Street. Durham, NC: Duke University Press.

Holmes, D. (2013) Economy of Words: Communicative Imperatives in Central Banks. Chicago, IL: University of Chicago Press.

Jameson, F. (1997) Culture and finance capital. Critical Inquiry, 24(1): 236-65.

Joseph, M. (2014) Debt to Society: Accounting for Life Under Capitalism. Minneapolis, MN: University of Minnesota Press.

Konings, M. (2015) The Emotional Logic of Capitalism: What Progressives Have Missed. Stanford, CA: Stanford University Press.

Konings, M. (2018) Capital and Time: For a New Critique of Neoliberal Reason. Stanford, CA: Stanford University Press.

Mehrling, P. (2010) The New Lombard Street: How the Fed Became the Dealer of Last Resort.

Princeton, NJ: Princeton University Press.

Mirowski, P. (2013) Never Let a Serious Crisis Go to Waste: How Neoliberalism Survived the Financial Meltdown. London: Verso.

Poovey, M. (1998) A History of the Modern Fact: Problems of Knowledge in the Sciences of Wealth and Society. Chicago, IL: University of Chicago Press.

Poovey, M. (2008) Genres of the Credit Economy: Mediating Value in Eighteenth-and NineteenthCentury Britain. Chicago, IL: University of Chicago Press.

Sohn-Rethel, A. (1978) Intellectual and Manual Labor: A Critique of Epistemology. London: Macmillan. 